\title{
Pembelajaran Pendidikan Agama Islam dengan Menggunakan Aplikasi Quiziz pada Era Covid-19
}

\author{
Armi Gusvita ${ }^{1 *}$ \\ Sekolah Menengah Atas Negeri 1 Batang Anai Padang Pariaman*1 \\ ${ }^{*}$ email: armigusvitaagpaii@gmail.com
}

\begin{abstract}
This article explains about the increased student activity during the covid-19 pandemic by using quiziz application in Islamic Religious Education learning. Quiziz has the advantage of being able to provide a pleasant atmosphere for students with music and pictures that change. Students will race in getting the highest rank because this quiziz uses a rating system. Playing games with this quiziz app can provide an experience for students. This research uses descriptive qualitative methods, data collection techniques used for observation, interviews and documentation. The results of this study showed the use of quiziz in PAI learning makes the activities and learning outcomes of students so increased, from 31 students who were previously only active 15 people, but after using the quiziz application has increased and can also improve the learning results that were previously only completed 7 people, but after using the quiziz application to 20 student's.
\end{abstract}

Keywords: Covid-19, PAI Learning, Quiziz

Abstrak

Artikel ini menjelaskan tentang aktivitas peserta didik meningkat di masa pandemi covid-19 dengan menggunakan aplikasi quiziz dalam pembelajaran Pendidikan Agama Islam. Quiziz ini mempunyai kelebihan dapat memberikan suasana yang menyenangkan bagi peserta didik dengan musik dan gambarnya yang berganti-ganti. Peserta didik akan berpacu dalam mendapatkan peringkat yang tertinggi karena quiziz ini memakai system peringkat. Bermain game dengan aplikasi quiziz ini dapat memberikan pengalaman bagi peserta didik. Penelitian ini menggunakan metode kualitatif deskriptif, teknik pengumpulan data yang digunakan observasi, wawancara dan dokumentasi. Hasil penelitian ini menunjukkan penggunaan quiziz dalam pembelajaran PAI membuat aktivitas dan hasil belajar peserta didik
Artikel Info

Received:

21 February 2021

Revised:

02 April 2021

Accepted:

04 June 2021

Published:

10 June 2021 
jadi meningkat, dari 31 peserta didik yang sebelumnya hanya aktif 15 orang, namun setelah menggunakan aplikasi quiziz sudah meningkat dan juga dapat meningkatkan hasil pembelajaran yang sebelumnya hanya tuntas 7 orang, namun setelah menggunakan aplikasi quiziz menjadi 20 peserta didik.

\section{Kata Kunci: Covid-19, pembelajaran PAI, Quiziz.}

\section{A. Pendahuluan}

Pandemic Covid-19 di Indonesia berimbas pada beberapa aspek kehidupan, mulai dari aspek sosial, ekomnomi, kehidupan beragama, bahkan sampai kepada aspek pendidikan (Ritonga et al., 2021). Dalam menyikapi wabah pandemi Covid-19 ini, Pemerintah Negara Indonesia menetapkan social distancing (Mursal et al., 2021) atau di Indonesia lebih dikenal sebagai physical distancing (menjaga jarak) (Putra et al., 2020), bahkan beberapa daerah/provinsi sampai mengambil kebijakan Pembatasan Berskala Besar (PSBB) untuk meminimalisir persebaran pandemi Covid-19 (Akmal \& Ritonga, 2020).

Menindaklanjuti kebijakan

Pemerintah Indonesia ini, Kementerian Pendidikan dan Kebudayaan (Kemendikbud) mengambil langkah dan kebijakan untuk belajar dari rumah melalui pembelajaran daring (dalam jaringan) (Rizaldi \& Fatimah, 2020), untuk menghindari persebaran pandemi wabah Covid-19 ini. Pembelajaran tatap muka diganti dengan pembelajaran dalam jaringan (daring) (Giatman et al., 2020), (Wakil et al., 2019).

Melakukan kegiatan belajar mengajar dengan jarak jauh membutuhkan strategi atau cara tersendiri agar peserta didik belajar dari rumah ini dapat ikut ber peran aktif, tidak sedikit di antara peserta didik dengan berbagai alasan tidak hadir dalam pembelajaran during (Wart et al., 2020).

Kementerian Pendidikan dan Kebudayaan (Kemendikbud) RI, telah melakukan kerjasama dengan 12 platform pembelajaran dalam jaringan (daring) ini dalam menyediakan aplikasi pembelajaran dalam jaringan (daring) untuk seluruh peserta didik di Indonesia (Hakim, 2020). 12 platform atau aplikasi tersebut adalah: Rumah Belajar. 
MejaKita. Quipper School. Ruangguru. Zenius. Zenius. Dan kelas maya sicadiak pandai (Handarini \& Wulandari, 2020). Setelah penulis memakai kelas maya sicadiak pandai yang merupakan bagian dari rumah belajar namun media ini belum membuat peserta didik tertarik dan aktif.

Kondisi covid-19 semakin menambah kurangnya motivasi dan semangat belajar bagi peserta didik karena prosesnya yang dilaksanakan secara jarak jauh, hal ini semakin mempersulit akan tercapainya tujuan pembelajaran PAI yang selama ini masih banyak dipertanyakan oleh berbagai pihak (Elsa et al., 2019), (Fadlilah, 2017), (Nugraha et al., 2020).

Realita kurangnya keaktifan peserta didik dalam belajar maka tentu akan mempengaruhi hasil belajar pendidikan agama Islam yang dilakukan, sebagaimana hasil penelitian telah membuktikan bahwa keaktifan peserta didik dalam proses pembelajaran akan berdampak pada hasil belajar (Ningsih et al., 2017). Sesuai dengan permasalahan di atas maka penulis mencari lagi cara agar peserta didik dapat ikut serta dan berperan aktif dalam belajar, untuk itu penulis menggunakan game quiziz untuk menarik perhatian peserta didik agar dapat aktif dalam pembelajaran pendidikan Agama Islam. Dengan memanfaatkan game quiziz peserta didik dapat mengulang-ulang pelajaran yang sudah diberikan oleh pendidik, dan dapat meningkatkan aktivitas peserta didik dalam belajar di masa new normal. Maka dari itu penulis memberikan metode pembelajaran dengan cara bermain game dengan memanfaatkan aplikasi quiziz.

Penulis menggunakan game Quiziz untuk meningkatkan aktivitas peserta didik dan ketertarikkannya belajar khususnya dalam Pembelajaran Pendidikan Agama Islam. Belajar merupakan suatu kegiatan yang di terapkan di sekolah sehari-hari (Nurkaman \& Permana, 2018). Salsabila dkk telah membuktikan bahwa penggunaan quiziz dalam pembelajaran sangat efektif, pernyataan mereka didasarkan pada penggunaan handphone yang selama ini lebih mengarah pada permainan sia-sia, namun dengan quiziz perhatian beralih kepada belajar, kemampuan peserta didik dalam memahami soal secara baik (Salsabila et al., 2020). Hotmaida dkk juga membuktikan bahwa kemampuan guru dalam memilih metode dan strategi yang 
ISSN 1979-9950 (print) || ISSN 2598-0033 (online), http://jurnal.umsu.ac.id/index.php/intiqad

DOI: intiqad.v\%vi\%i.6582

Vol. 13, No. 1 (June 2021)

tepat menjadikan peserta didik semakin termotivasi dalam pembelajaran (Hotmaida et al., 2020).

Sejalan dengan beberapa temuan di atas, kondisi covid-19 mengharuskan guru untuk memiliki kreativitas dan inovasi dalam pembelajaran. Dan pembelajaran yang dilangsungkan melalui during harus memaksimalkan perangkat teknologi, karena teknologi dalam pembelajaran dapat dijadikan sebagai alternative untuk menjangkau hal-hal yang tidak dapat dijangkau secara tatap muka (Ritonga et al., 2016).

Penelitian ini akan difokuskan pada penggunaan quiziz sebagai bagian dari platform pembelajaran berbasis teknologi khususnya pembelajaran PAI di masa covid-19. Temuan penelitian ini akan dapat dijadikan sebagai tawaran bagi guru untuk menjadikan platform quiziz sebagai metode dalam mengurangi kebosanan peserta didik.

\section{B. Metode Penelitian}

Untuk mendapatkan tujuan penelitian yang dijelaskan di atas, penelitian ini dilaksanakan di SMAN 1 Batang Anai Padang Pariaman, pemilihan tempat ini dikarenakan realita tentang problem yang peneliti lihat selama

melaksanakan

proses

pembelajaran pendidikan agama Islam melalui during.

Penelitian ini dilakukan sejak bulan agustus sampai bulan Desember 2020 di SMAN 1 Batang Anai, sumber data yang digunakan adalah peserta didik, dan guru pendidikan agama Islam, sedangkan teknik pengumpulan data yang digunakan yaitunya obsevasi, wawancara dan dokumentasi. Sementara analisis data yang digunakan adalah kualitatif deskriptif dan pencermatan keabsahan data di lakukan dengan triangulasi (sumber, waktu, metode).

\section{Hasil Dan Pembahasan}

Quiziz merupakan aplikasi berbasis game yang membuat aktivitas kelas dan menjadikan pembelajaran lebih menyenangkan dan lebih interaktif. Untuk menarik perhatian peserta didik pada pelajaran pendidikan Agama Islam agar masuk kelas online atau banyak beraktifitas mengikuti pembelajaran Pendidikan Agama Islam penulis mencoba menggunakan game quiziz.

Penulis menggunakan Aplikasi game quiziz ini seperti yang kita ketahui peserta didik yang di hadapi sekarang ini peserta didik yang hidup di zaman 
INTIQAD: JURNAL AGAMA DAN PENDIDIKAN ISLAM

ISSN 1979-9950 (print) || ISSN 2598-0033 (online), http://jurnal.umsu.ac.id/index.php/intiqad

DOI: intiqad.v\%vi\%i.6582

Vol. 13, No. 1 (June 2021)

teknologi yang sedang berkembang. Mereka cendrung bermain game maka itu penulis menggunakan game quiziz ini untuk menarik perhatian peserta didik agar bisa hadir di kelas online pendidikan Agama Islam. Setelah mereka tertarik berarti sudah mengikuti aktivitas dalam pembelajaran Pendidikan Agama islam. Dengan Aktivitas yang tinggi maka akan dapat meningkatkan hasil belajar peserta didik.

Untuk Pembuatan Game quiziz online ini tentu pendidik terlebih dahulu harus membuat game quiziznya.

Pelaksanaan awalnya pendidik menyiapkan game quiziz yang berhubungan dengan mata pelajaran atau materi ajar terlebih dahulu (Panggabean \& Harahap, 2020). Langkah- langkah atau cara menggunakan quziziz terlebih dahulu pastikan pendidik memiliki dan menggunakan emailnya (The \& Usagawa, 2018).

1. Klik crome ketik Quiziz.com lalu login.

2. Masuk dengan menggunakan email dan kemudian masuk sebagai peran guru.

3. Lengkapi data data kita dan mulai membuat soal atau mengambil soal dari quiziz yang ada.
4. Siapkan soal dan jawabannya atau kuncinya cara membuat soal.

\section{Gambar 1. Klik Create akan tampil}

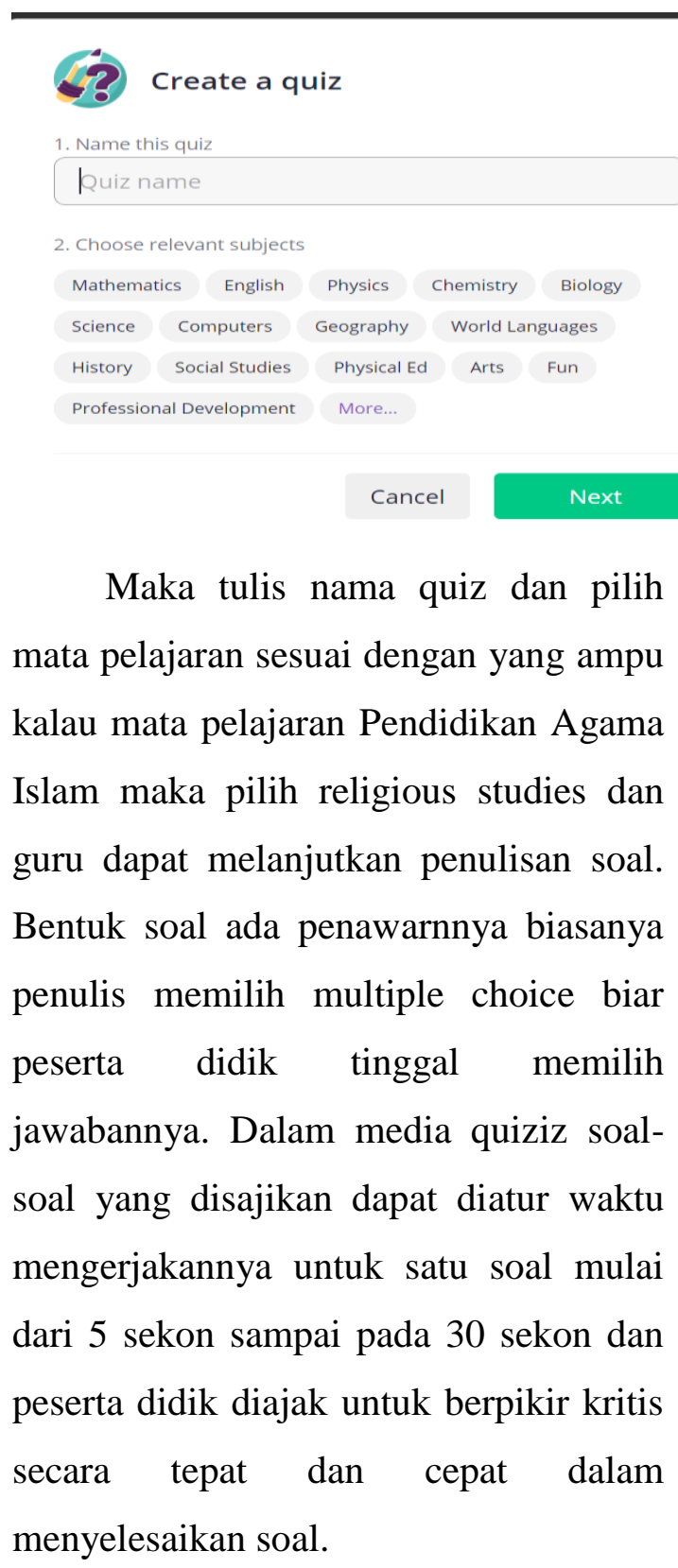


INTIQAD: JURNAL AGAMA DAN PENDIDIKAN ISLAM

ISSN 1979-9950 (print) || ISSN 2598-0033 (online), http://jurnal.umsu.ac.id/index.php/intiqad

DOI: intiqad.v\%vi\%i.6582

Vol. 13, No. 1 (June 2021)

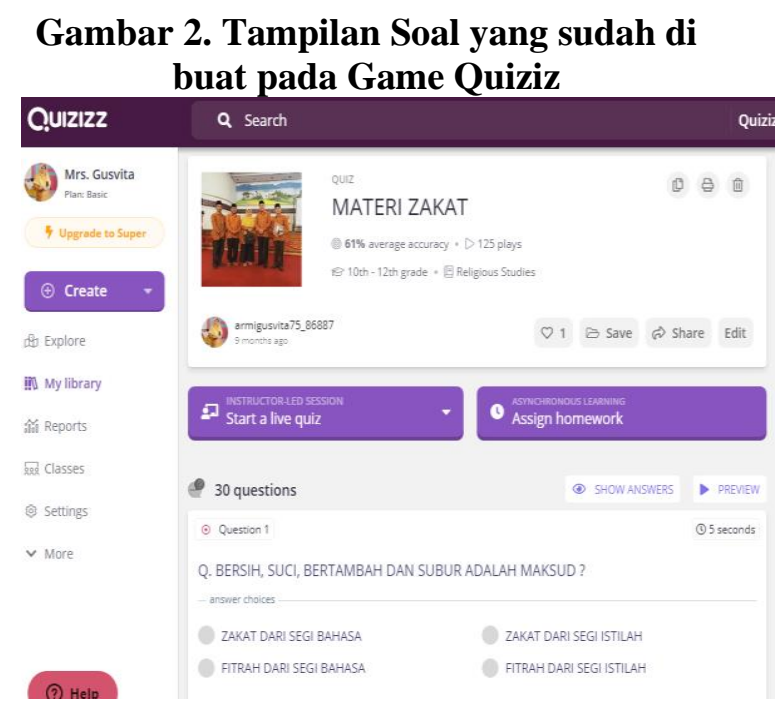

Cara pendidik mengirimkan quiziz ini klik jika langsung klik star a live quiz selanjutnya klil clasik, klik continue maka akan keluar kode, sebagaimana yang terlihat pada gambar 3 di bawah ini:

Gambar 3. Tampilan Pengiriman Kode Join Quiziz

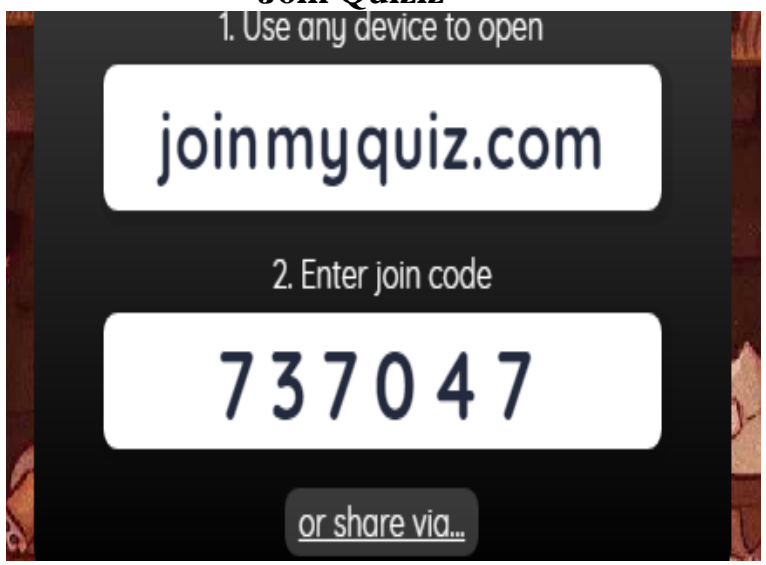

Kode di atas yang akan dikirim pada peserta didik.

Pada tampilan jawaban soal yang ada pada tampilan quiziz peserta didik di beri warna yang berbeda beda dan di beri gambar. Pada computer pendidik sebagai operator dan pada peserta didik akan terlihat soal yang di acak secara otomatis sehingga peserta didik tidak dapat bekerjasama. Sedangkan pada layar monitor pendidik akan terlihat pergerakkan perpacuan peserta didik dalam menjawab pertanyaan. Untuk pelaksanaan belajar pendidikan agama islam dengan menggunakan quiziz ini dapat di lakukan secara langsung dengan mengirimkan kodenya pada peserta didik dapat kirimkan kodenya melalui classroom serta dapat di kirim kan atau di tempelkan linknya pada google site. Namun penulis sering melakukan di masa pandemi ini secara langsung peserta didik mengerjakannya setelah mendapat instruksi lewat whatshap group. Kita mempergunakan whatshap group karena kita belajar dari rumah.

Setelah kode dikirim pada peserta didik, maka peserta didik klik google ketik quiziz pilih join, untuk join di quiziz setelah kita bagikan kode kuiz pada whatshab group peserta didik akan memasukkan nama dan kode yang ada untuk dapat bermain game quiziz. Jika sudah ada peserta yang masuk maka pendidik sebagai operator memulai quiz dengan menekan star. 
INTIQAD: JURNAL AGAMA DAN PENDIDIKAN ISLAM

ISSN 1979-9950 (print) || ISSN 2598-0033 (online), http://jurnal.umsu.ac.id/index.php/intiqad DOI: intiqad.v\%vi\%i.6582

Vol. 13, No. 1 (June 2021)

Pendidik secara langsung dapat melihat keaktifan peerta didik sewaktu peserta didik masuk dan bermain game quiziz. Pendidik akan melihat peserta didik secara langsung berlomba lomba dalam mengerjakan soal. Dalam menyelesaikan soal-soal dengan quiziz ini peserta didik diiringi dengan music yang sudah otomatis adanya sehingga peserta didik merasa tidak terbebankan. Seperti yang terlihat pada gambar.

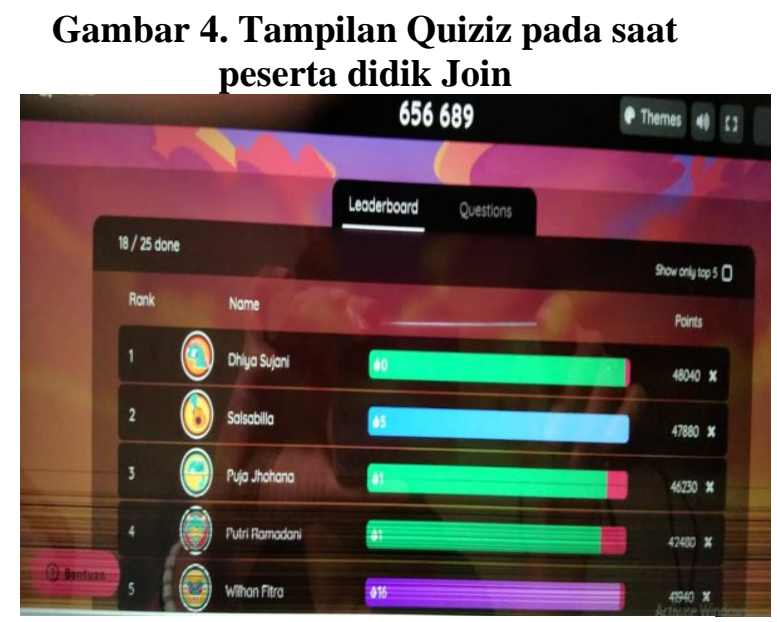

Gambar di atas merupakan peserta didik dalam berlomba menyelesaikan soal soal yang dapat dipantau oleh pendidik. Setelah berakhirnya waktu pelaksanaan nya maka peserta didik akan dapat melihat hasil juaranya seperti gambar di bawah ini:
Gambar 5. Aktivitas dan Semangat Peserta Didik dalam Menyelesaikan Soal

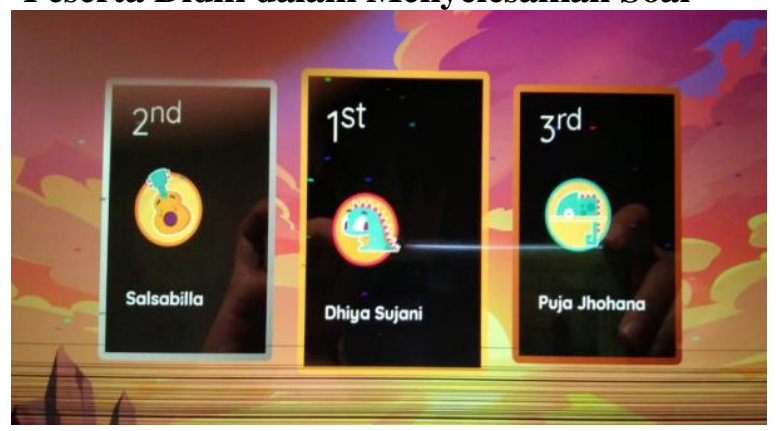

Dalam pembelajaran pendidikan agama Islam, peneliti memanfaatkan quiziz untuk mengulang-ulang pelajaran yang sudah diberikan atau dapat juga di gunakan untuk penilaiaan harian tujuannya untuk dan dapat meningkatkan aktivitas pesertaa didik dalam belajar di masa new normal. Dengan menggunakan game quiziz peserta didik dapat belajar kapan saja dan di mana saja dan dapat di jadikan pekerjaan rumah dengan membatasi waktu mengerjakannya.

Namun untuk memanfaatkan game quiziz ini memang membutuhkan jaringan internet namun tanpa jaringan intenet maka game quiziz ini tidak dapat di gunakan. Dengan perkembangan teknologi dapat mempemudah guru dalam melaksanakan tugas namun disisi lain melaksanakan pembelajaran dengan system teknologi kurangnya interaksi antara pendidik dan peserta didik. Untuk mendekatkan pendidk dan peserta didik dan membuat peserta didik untuklebih 
aktif dalam pembelajaran salah satunya dengan menggunakan aplikasi game quiziz.

Quizizi merupakan media pembelajaran yang menarik, media ini dapat meningkatkan semangat atau aktivitas peserta didik dalam belajar. Sistem rangking dalam dalan quiziz memotivasi peserta didik untuk menjawab dengan benar dan teliti.

Quiziz ini mempunyai kelebihan dapat memberikan suasana yang menyenangkan bagi peserta didik dengan musik dan gambarnya yang berganti-ganti. Peserta didik akan berpacu dalam mendapatkan peringkat yang tertinggi karena quiziz ini memakai system peringkat. Bermain game dengan aplikasi quiziz ini dapat memberikan pengalaman bagipeserta didik. Dan jika setelah selesai peserta didik mengerjakan soal- soalnya dapat kita dapatkan data spredsheetnya dalam bentuk excel dan pendidik pun mendapatkan data analisis dari soal yang terjawab dan tidak terjawab oleh peserta didik.

Quiziz merupakan aplikasi berbasis game yang membuat aktivitas kelas dan menjadikan pembelajaran lebih menyenangkan dan lebih interaktif (Zhao, 2019), (Pahamzah et al., 2020).
Dari hasil yang penulis dapatkan setelah menggunakan game quiziz ini untuk pembelajaran Pendidikan Agama Islam khususnya, maka peserta didik lebih aktif untuk belajar ini di buktikan dengan kehadiran peserta didik, pada waktu sebelumnya peserta didik hadir 15 orang dari 31 orang ini terjadi pada pertemuan pertama, namun pada pertemuan keduanya penulis menggunakan game quiziz ini sebelum belajar dan sesudah belajar, maka pertemuan kedua sudah ada penambahan kehadiran peserta didik.

Untuk Menarik perhatian dan meningkatkan keaktivan peserta didik maka penulis melaksanakan pembelajaran dengan menggunakan game quiziz unntuk mengulang dan mengingat-ingatkan materi yang sudah di sampaikan. Penulis berikan bermain game quiziz ini di awal dan diakhir pembelajaran. Hasil yang di dapat dari kehadirannya dari 31 orang peserta didik maka sudak hadir 30 orang dan nilainya pun lebih meningkat. Disini nampak meningkatnya aktivitas peserta didik dan dari keaktivan yang meningkat akan berpengaruh pada peningkatan hasil belajar peserta didik. Dapat di lihat pada lampiran dari perbandingan keaktifan 


\section{INTIQAD: JURNAL AGAMA DAN PENDIDIKAN ISLAM}

ISSN 1979-9950 (print) || ISSN 2598-0033 (online), http://jurnal.umsu.ac.id/index.php/intiqad DOI: intiqad.v\%vi\%i.6582

Vol. 13, No. 1 (June 2021)

peserta didik dari perolehan nilai sebelum menggunakan metode game quiziz dalam penilaiaan kognitif dari 31 orang peserta didik yang mendapat nilai di atas kkm sebanyak 7 orang setelah di gunakan game quiziz untuk memicu keaktivan peserta didik nilainya meningkat dari 31 orang peserta didik tuntas 20 orang.

Perbandingan nilai sebelum dan setelah menggunakan quiziz.

\section{Table 1. Perbandingan Hasil Belajar PAI sebelum dan Sesudah Penggunaan Quiziz}

$\begin{array}{llll}\text { Mapel } & : \text { PAI } & \text { KKM } & : 75 \\ \text { Kelas } & : \text { XII. } & \text { Guru } & : \text { AG }\end{array}$

\begin{tabular}{|c|l|c|c|}
\hline \multirow{2}{*}{ NO } & \multirow{2}{*}{ Koding } & \multicolumn{2}{|c|}{ Nilai } \\
\cline { 3 - 4 } & & Sebelum & Sesudah \\
\hline 1 & ABK & 83 & 98 \\
\hline 2 & ABU & 30 & 90 \\
\hline 3 & AZ & 80 & 86 \\
\hline 4 & CAY & 42 & 94 \\
\hline 5 & DSA & 35 & 82 \\
\hline 6 & DS & 71 & 80 \\
\hline 7 & EDA & 81 & 82 \\
\hline 8 & FYN & 65 & 78 \\
\hline 9 & FS & 64 & 80 \\
\hline 10 & FSE & 63 & 56 \\
\hline 11 & GR & 19 & 74 \\
\hline 12 & HAA & 79 & 32 \\
\hline 13 & HNS & 43 & 86 \\
\hline
\end{tabular}

\begin{tabular}{|l|l|c|c|}
14 & IW & 47 & 86 \\
\hline 15 & MGF & 29 & 76 \\
\hline 16 & MAP & 85 & 62 \\
\hline 17 & MOP & 42 & 0 \\
\hline 18 & MJP & 79 & 64 \\
\hline 19 & MAPu & 65 & 92 \\
\hline 20 & MS & 70 & 64 \\
\hline 21 & Nr & 29 & 66 \\
\hline 22 & NUU & 31 & 86 \\
\hline 23 & NH & 29 & 72 \\
\hline 24 & PA & 48 & 66 \\
\hline 25 & RAP & 75 & 82 \\
\hline 26 & RA & 27 & 88 \\
\hline 27 & SR & 60 & 92 \\
\hline 28 & Sel & 33 & 88 \\
\hline 29 & UW & 57 & 4 \\
\hline 30 & WRP & 32 & 98 \\
\hline 31 & Yol & 10 & 88 \\
\hline
\end{tabular}

Dari gambaran hasil belajar sebelum dan sesudah penggunaan quiziz dalam pembelajaran PAI dapat ditegaskan bahwa quiziz dapat meningkatkan aktivitas belajar peserta didik sehingga hasil yang mereka peroleh juga semakin meningkat. Temuan ini sesuai dengan yang diungkapkan oleh Salsabila dkk bahwa quiziz berdampak terhadap hasil belajar yang didapatkan oleh peserta didik (Salsabila et al., 2020). 
Hasil penggunaan quiziz yang dijelaskan di atas juga menguatkan beberapa temuan tentang penggunaan aplikasi online dalam pembelajaran yang tidak hanya sebatas mengisi kewajiban sebagai pendidik, melainkan berorientasi pada pencapaian tujuan pembelajaran (Sukarno \& Widdah, 2020). Ross dan kawan-kawan juga telah menjelaskan bahwa dengan menggunakan quiziz motivasi belajar serta hasil yang diperoleh peserta didik akan semakin meningkat (Ross et al., 2018).

Aspek terpenting dari penelitian ini ialah bahwa pembelajaran yang berkualitas akan tetap tercapai ketika guru memiliki kreativitas dan kerjasama yang baik dengan para orang tua dan peserta didik. Pandangan ini semakin memperkuat temuan dari Suparman dan kawa-kawan yang mengingatkan bahwa belajar dimasa covid-19 tidak akan mungkin dapat berlangsung secara baik tanpa adanya kerjasama dari berbagai pihak (Suparman et al., 2020).

Quiziz yang telah dirancang dan digunakan guru seabagaimana hasil penelitian ini mesti dilakukan upaya inovasi, karena peserta didik akan memiliki rasa bosan ketika model, materi dan bentuk quiziz yang digunakan tidak dilakukan pembaharuan (Suharsono, 2020). Dan inilah sesungguhnya dampak penggunaan teknologi dalam pembelajaran yang membutuhkan inovasi secara berkesinambungan, jika guru tidak mampu untuk itu maka kemampuannya dalam memanfaatkan teknologi akan terlampaui oleh peserta didik (Mckenney \& Visscher, 2019), (Ritonga et al., 2020), (Thieman, 2008).

Dari hasil penelitian juga terdapat makna yang menunjukkan urgensi pemilihan media dan strategi pembelajaran yang tepat, hal ini dikarenakan bahwa pada satu sisi quiziz dipahami sebuah media pembelajaran yang bermanfaat sebagai penghantar antara guru dan peserta didik dalam penyampaian materi pembelajaran (Akhtar et al., 2019). Oleh karena itu, guru pendidikan agama Islam mesti memiliki kompetensi dalam penggunaan berbagai media yang berbasis teknologi untuk mendukung terlaksananya proses pembelajaran yang berkualitas.

\section{Penutup}

Penggunaan media pembelajaran dengan sepert game quiziz ini untuk meningkatkan aktivitas peserta didik di 
SMAN 1 batang Anai dalam pembelajaran Pendidikan Agama Islam dapat terlaksana dengan baik, dengan meningkatnya aktivitas peserta didik maka meningkat pula hasil belajar peserta didik. Pada mata pelajaran Pendidikan agama Islam. Jadi dapat diambil kesimpulan jika peserta didik aktif dalam pembelajaran maka hasil akhirnya akan meningkat, maka untuk menarik perhatian peserta didik dalam proses pembelajaran terutama di masa new normal ini penulis menggunakan metode pembelajaran dengan menggunakan aplikasi game quiziz.

Rekomendasi yang dapat diberikan penggunaan media pembelajaran game quiziz ini dalam pelajaran pendidikan agama Islam agar dapat pula di manfaatkan oleh semua pendidik untuk memudahkan peserta didik dan pendidik dalam proses pembelajaran.

\section{E. Daftar Pustaka}

Akbar, E. (2002). Metode Belajar Anak Usia Dini. Jakarta: Prenada Media.

Al-Jauziyyah, I. Q. (2014). Tuhfatul Maudud bi Ahkam Maulid. Jakarta: Ummul Qura.

Asrori, M. M. (1983). Terjemah Barsanji. Surabaya: Mitra Umat.
Az-Zuhaili, W. (1991). Tafsir al-Munir fi al- 'aqidah wa asySyar iah wa alManhaj. Damaskus: Darul Fikri.

Darajat, Z. (1992). Pendidikan Islam dalam Keluarga dan Sekolah. Jakarta: Ruhama.

Fadillah, M. (2013). Pendidikan Karakter Anak Usia Dini. Yogyakarta: Ar-Ruzz Media.

Faizah, N. (2008). Sejarah Al-Qur'an. Jakarta: Artharivera.

Fatah, A. (2009). 40 Metode Pendidikan dan Pengajaran Rasulullah , (Bandung: , 2009), h. 79. Bandung.

Halim, M. N. A. (2001). Anak Soleh Dambaan Keluarga. Yogyakarta: Mitra Pustaka.

Hamka. (1992). Tafsir Al-Azhar. Jakarta: Pustaka Panjimas.

Ma'shumah, L. A. (2001). Pembinaan Kesadaran Beragama Pada Anak. Yogyakarta: Pustaka Belajar.

Masganti. (2015). Psikologi Agama. Medan: Perdana Publishing.

Mursid. (2009). Kurikulum dan Pendidikan Anak Usia Dini (PAUD) Sebuah Harapan Masyarakat. Semarang: Aktif Media.

Sanusi, A. (2016). Metodologi Penelitian Bisnis. Jakarta: Salemba Empat.

Sanusi, U. (2012). Ilmu Pendidikan Islam. Yogyakarta: Deepublish. 
INTIQAD: JURNAL AGAMA DAN PENDIDIKAN ISLAM

ISSN 1979-9950 (print) || ISSN 2598-0033 (online), http://jurnal.umsu.ac.id/index.php/intiqad

DOI: intiqad.v\%vi\%i.6582

Vol. 13, No. 1 (June 2021)
Setiawan, H. R. (2017). Pengaruh Konsep Diri, Minat dan Inteligensi Terhadap Hasil Belajar Mahasiswa Pada Mata Kuliah Metode Pengembangan Kemampuan Bahasa Anak. Intiqad: Jurnal Agama Dan Pendidikan Islam, 9(2), 23.

Shalih, A. H. (2008). Mendidik anak laki-laki. Jakarta: Gema Insani
Press.

Shihab, M. Q. (2012a). Kaidah Tafsir. Jakarta: Lentera Hati.

Shihab, M. Q. (2012b). Tafsir AlMisbah. Jakarta: Lentera Hati.

Yusuf, S. (2018). Psikologi Perkembangan. Bandung: Remaja Rosdakarya. 